\title{
Histopathological Study of the Gall Bladder
}

\author{
Dr. Shreesha Khandige, Suchithra A. Shetty ${ }^{*}$ \\ Professor and HOD, Department of Pathology, Kanachur Institute of Medical Sciences, Mangalore India
}

DOI: $10.36348 /$ sjpm.2020.v05i02.006 | Received: 03.02.2020 | Accepted: 10.02.2020 | Published: 14.02 .2020

*Corresponding author: Suchithra A Shetty

\section{Abstract}

Gall bladder disease is rather encountered on a daily basis in the OPD's now a day[1]. Many of these get admitted. Most of the cases admitted in the hospitals require radiological intervention. Routine examination of the gall bladder using USG is difficult and challenging. After cholecystectomy has been done it shows different histopathological changes ranging from inflammation to premalignant and carcinoma. This study puts in an effort to find the answer for the same.

Keywords: Gall bladder, Pathology, Histopathological.

Copyright @ 2020: This is an open-access article distributed under the terms of the Creative Commons Attribution license which permits unrestricted use, distribution, and reproduction in any medium for non-commercial use (NonCommercial, or CC-BY-NC) provided the original author and sources are credited.

\section{INTRODUCTION}

Inflammation causes the majority of gallbladder diseases due to irritation of the gallbladder walls, which is known as cholecystitis [1-3]. This inflammation is often due to gallstones blocking the ducts leading to the small intestine and causing bile to build up. It may eventually lead to necrosis (tissue destruction) or gangrene. There are many different types of gallbladder disease [1,2]. Gall bladder disease is rather encountered on a daily basis in the OPD's now a day. Many of these get admitted. Most of the cases admitted in the hospitals require radiological intervention. Routine examination of the gall bladder using USG is difficult and challenging [4-6]. After cholecystectomy has been done it shows different histopathological changes ranging from inflammation to premalignant and carcinoma [7]. This study puts in an effort to find the answer for the same.

\section{AIMS AND OBJECTIVES}

To study the Histopathological reports which are considered to be the gold standard for Gall Bladder Pathologies?

\section{MATERIALS AND METHODS}

The study was done in Kanachur Institute of Medical Sciences, Deralakatte, and Mangalore. The duration of the study is for a period of 18 months from September 2016 to April 2018.

One hundred twenty patients who came to Radiological Diagnosis and showed signs of gall bladder diseases in different Departments and ultimately were operated for the same

\section{Inclusion Criteria}

Patients with gall bladder disease

\section{Exclusion Criteria}

Non co-operative patients

The reports were checked both retrospectively as well as prospectively and then reported.

\section{RESULTS}

Table-1: Age Distribution

\begin{tabular}{|l|l|l|}
\hline Number & Mean age & Std Deviation \\
\hline 120 & 42.65 years & 6.4 years \\
\hline
\end{tabular}

Table-2: Sex Distribution

\begin{tabular}{|l|l|l|}
\hline Number & Male & Female \\
\hline 120 & 59 & 41 \\
\hline
\end{tabular}

\section{Diagnosis by Histopathology}

Chronic Calculous Cholecystitis - 77

Chronic Cholecystitis Cholesterolosis - 21

Follicular Cholecystitis -1

Acute Calculous Cholecystitis - 5

Acute Acalculous Cholecystitis - 1

Chronic Cholecystitis with Evidence of Intestinal Metaplasia - 1

Gall Bladder shows Poor Presentation with Autolytic

Changes and Feature of Chronic Cholecystitis -2

Xantho Granulomatous Cholecystitis - 2

Chronic Cholecystitis with Dysplastic Changes - 3 
Chronic Cholecystitis with Nonspecific Lymphadenitis $-1$

Eosinophilic Cholecystitis - 5

Adenocarcinoma of Gall Bladder - 1

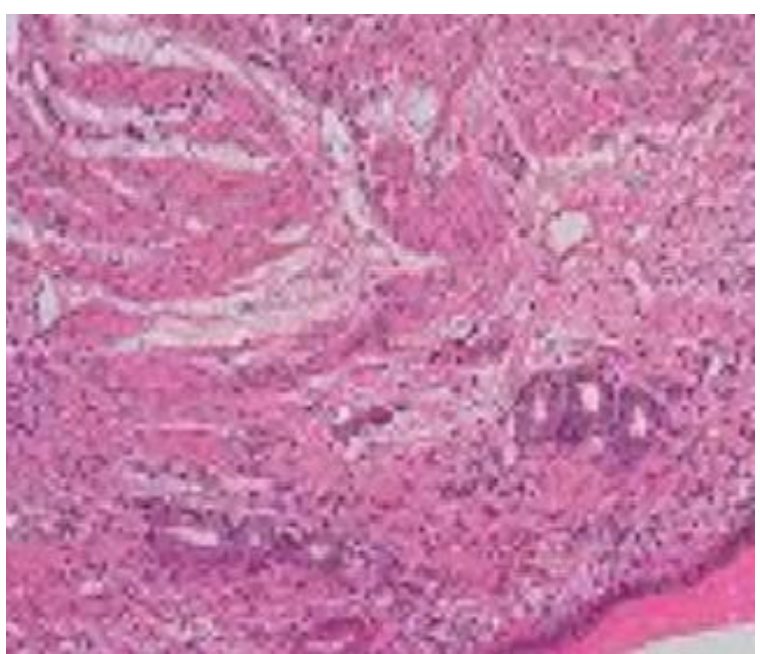

Image-1: Chronic Cholecystitis

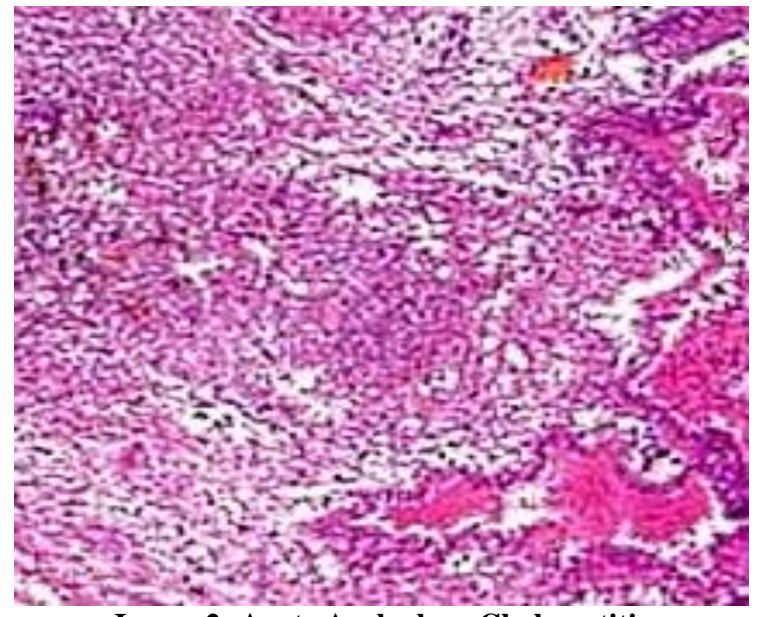

Image 2: Acute Acalculous Cholecystitis

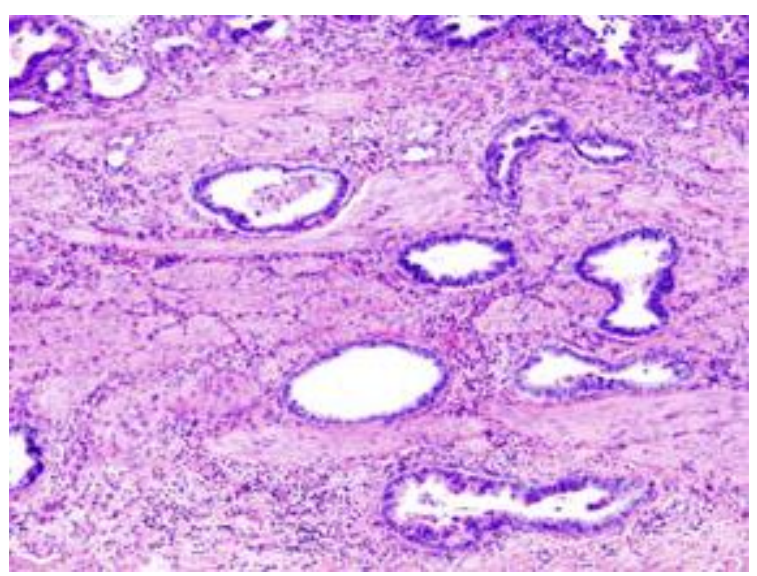

Image-3: Adenocarcinoma of Gall Bladder

\section{DISCUSSION}

There are many different types of gallbladder

\section{Gallstones}

Gallstones develop when substances in the bile (such as cholesterol, bile salts, and calcium) or substances from the blood (like bilirubin) form hard particles that block the passageways to the gallbladder and bile ducts.

Gallstones also tend to form when the gallbladder doesn't empty completely or often enough. They can be as small as a grain of sand or as large as a golf ball.

\section{Numerous factors contribute to your risk of} gallstones. These include

- being overweight or obese

- having diabetes

- being age 60 or older

- taking medications that contain estrogen

- having a family history of gallstones

- being female

- having Crohn's disease and other conditions that affect how nutrients are absorbed

- having cirrhosis or other liver diseases

\section{Cholecystitis}

Cholecystitis is the most common type of gallbladder disease. It presents itself as either an acute or chronic inflammation of the gallbladder.

\section{Acute cholecystitis}

Acute cholecystitis is generally caused by gallstones. But it may also be the result of tumors or various other illnesses.

It may present with pain in the upper right side or upper middle part of the abdomen. The pain tends to occur right after a meal and ranges from sharp pangs to dull aches that can radiate to your right shoulder. Acute cholecystitis can also cause:

- fever

- nausea

- $\quad$ vomiting

- jaundice

\section{Chronic cholecystitis}

After several attacks of acute cholecystitis, the gallbladder can shrink and lose its ability to store and release bile. Abdominal pain, nausea, and vomiting may occur. Surgery is often the needed treatment for chronic cholecystitis.

\section{Choledocholithiasis}

Gallstones may become lodged in the neck of the gallbladder or in the bile ducts. When the gallbladder is plugged in this way, bile can't exit. This may lead to the gallbladder becoming inflamed or distended. The plugged bile ducts will further prevent bile from traveling from the liver to the intestines. disease. 


\section{Choledocholithiasis can cause}

- extreme pain in the middle of your upper abdomen

- fever

- chills

- nausea

- vomiting

- jaundice

- $\quad$ pale- or clay-colored stools

\section{Acalculous gallbladder disease}

Acalculous gallbladder disease is inflammation of the gallbladder that occurs without the presence of gallstones. Having a significant chronic illness or serious medical condition has been shown to trigger an episode.

Symptoms are similar to acute cholecystitis with gallstones. Some risk factors for the condition include:

- $\quad$ severe physical trauma

- heart surgery

- abdominal surgery

- $\quad$ severe burns

- autoimmune conditions like lupus

- blood stream infections

- receiving nutrition intravenously (IV)

- $\quad$ significant bacterial or viral illnesses

\section{Biliary dyskinesia}

Biliary dyskinesia occurs when the gallbladder has a lower-than-normal function. This condition may be related to ongoing gallbladder inflammation.

Symptoms can include upper abdominal pain after eating, nausea, bloating, and indigestion. Eating a fatty meal may trigger symptoms. There are usually no gallstones in the gallbladder with biliary dyskinesia.

Your doctor may need to use a test called a HIDA scan to help diagnosis this condition. This test measures gallbladder function. If the gallbladder can only release 35 to 40 percent of its contents or less, then biliary dyskinesia is usually diagnosed.

\section{Sclerosing cholangitis}

Ongoing inflammation and damage to the bile duct system can lead to scarring. This condition is referred to as sclerosing cholangitis. However, it's unknown what exactly causes this disease.

Nearly half the people with this condition don't have symptoms. If symptoms do occur, they can include:

- fever

- jaundice

- $\quad$ itching

- upper abdominal discomfort.
Approximately 60 to 80 percent Trusted Source of people with this condition also have ulcerative colitis. Having this condition does increase the risk of liver cancer as well. Currently, the only known cure is a liver transplant.

Medications that suppress the immune system and those that help break down thickened bile can help manage symptoms.

\section{Gallbladder cancer}

Cancer of the gallbladder is a relatively rare disease. There are different types of gallbladder cancers. They can be difficult to treat because they're not often diagnosed until late in the disease's progression. Gallstones are a common risk factor for gallbladder cancer.

Gallbladder cancer can spread from the inner walls of the gallbladder to the outer layers and then on to the liver, lymph nodes and other organs. The symptoms of gallbladder cancer may be similar to those of acute cholecystitis, but there may also be no symptoms at all.

\section{Gallbladder polyps}

Gallbladder polyps are lesions or growths that occur within the gallbladder. They're usually benign and have no symptoms. However, it's often recommended to have the gallbladder removed for polyps larger than 1 centimeter. They have a greater chance of being cancerous.

\section{Gangrene of the gallbladder}

Gangrene can occur when the gallbladder develops inadequate blood flow. This is one of the most serious complications of acute cholecystitis. Factors that increase the risk of this complication include:

- being male and over 45 years old

- having diabetes

The symptoms of gallbladder gangrene can include:

- dull pain in the gallbladder region

- fever

- nausea or vomiting

- disorientation

- low blood pressure

\section{Abscess of the gallbladder}

Abscess of the gallbladder results when the gallbladder becomes inflamed with pus. Pus is the accumulation of white blood cells, dead tissue, and bacteria. Symptoms may include upper right-sided pain in the abdomen along with fever and shaking chills.

This condition can occur during acute cholecystitis when a gallstone blocks the gallbladder completely, allowing the gallbladder to fill with pus. It's more common in people with diabetes and heart disease. 


\section{CONCLUSION}

Radiological diagnosis of gall bladder is very high in sensitivity and specificity.

\section{REFERENCES}

1. Khoo, J.J., Nurul, A.M. (2008). A clinicopathological study of nine cases of gallbladder carcinoma in 1122 cholecystectomies in Johor, Malaysia. Malays J Pathol, 30(1):21-26.

2. Albores-Saavedra, J., Henson, D.E. (1986). Atlas of tumor pathology: tumors of the gallbladder and extrahepatic bile ducts. Second Series. Fascicle 22. 2nd edn. Bethesda, MD: Armed Forces Institute of Pathology, 28-123.

3. Greenberger, N.J., Paumgartner, G. (2011). Diseases of the gallbladder and bile ducts. Chap311. In: Longo DL, Fauci AS, Kasper DL, eds.
Harrison's principles of internal medicine. 18th edn. McGraw Hill Professional.

4. Friedman, L.S. (2015). Liver, Biliary Tract and Pancreas Disorders. In: Papadakis MA, McPhee SJ, Rabow MW, eds. Current medical diagnosis and treatment 2015. McGraw-Hill Education 2014

5. De, Zoysa, M.I.M., De, Silva, S.K.L.A., Illeperuma, A. (2010). Is routine histological examination of gallbladder specimen justifiable? Ceylon Medical Journal, 55(1):13-16.

6. Tantia, O., Jain, M., Khanna, S. (2009). Incidental carcinoma gallbladder during laparoscopic cholecystectomy for symptomatic gallstones disease. Surg Endosc, 23(9):2041-2046.

7. Khanna, R., Chansuria, R., Kumar, M. (2006). Histological changes in gallbladder due to stone disease. Indian J Surg. 68(4):201-204. 